\title{
EDUCAÇÃO EM SAÚDE E PERCEPÇÃO DA POPULAÇÃO DO ESTADO DO \\ AMAZONAS SOBRE A RAIVA HUMANA
}

\section{Vitória Elizabeth de Souza Rocha ${ }^{1}$; Deyrdre Nunes Merlo${ }^{1}$; Bianca Cristina Rocha de Oliveira $^{1}$; Rebeca Larissa Castro Silva²; Fabíola Pereira Firmino ${ }^{2}$; Jomel Francisco dos Santos ${ }^{3}$.}

${ }^{1}$ Médica Veterinária, Instituto Federal de Educação, Ciência e Tecnologia do Amazonas IFAM, Manaus, Amazonas.

${ }^{2}$ Acadêmica de medicina veterinária, Instituto Federal de Educação, Ciência e Tecnologia do Amazonas IFAM, Manaus, Amazonas.

${ }^{3}$ Professor Doutor, Médico Veterinário, Instituto Federal de Educação, Ciência e Tecnologia do Amazonas IFAM, Manaus, Amazonas.

DOI: 10.47094/IICNNESP.2021/168

\section{RESUMO}

A raiva é uma antropozoonose viral que se desenvolve de forma progressiva e aguda, cuja letalidade pode chegar a 100\%. Apesar da sua importância para a saúde pública, a mesma ainda é negligenciada. O objetivo deste trabalho foi divulgar informações a respeito da raiva humana, bem como, analisar a percepção do público amazonense, a fim de avaliar conhecimentos básicos da população acerca desta enfermidade. Foi utilizado como veículo para publicações interativas a página “@contraraiva_”, na rede social Instagram. Além disso, foi divulgado um questionário para a coleta de dados. $\mathrm{O}$ estudo alcançou 694 participantes cujas respostas ao questionário demonstraram baixo conhecimento sobre os ciclos de transmissão da doença e ocorrência de casos no estado. Portanto, a página pôde esclarecer informações a respeito da raiva humana e possibilitou a apuração de pontos importantes para elaboração de novas ações de educação em saúde focadas nas principais carências de informação da população.

PALAVRAS-CHAVE: Antropozoonose. Região Norte. Saúde Pública.

ÁREA TEMÁTICA: Educação em saúde.

\section{INTRODUÇÃO}

A raiva humana, também denominada encefalite rábica ou hidrofobia, possui como agente etiológico um vírus pertencente ao gênero Lyssavirus, e família Rhabdoviridae (VARGAS et al., 2019). Em sua maioria, os vírus rábicos são patogênicos para mamíferos, incluindo o homem e podem levar à ocorrência de encefalite (KIMURA; JÚNIOR, 2019). O vírus presente na saliva e secreções de animais infectados, pode ser transmitido ao homem por mordedura, arranhadura e lambedura (AZEVEDO et al., 2018). 
Instituído no Brasil em 1973, o Programa Nacional de Profilaxia da Raiva Humana proporcionou a diminuição dos casos de raiva humana e canina, em virtude da efetividade das campanhas de vacinação. Entretanto, é de grande preocupação os casos de raiva humana transmitidos por animais no ciclo silvestre (WADA; ROCHA; MAIA-ELKHOURY, 2011).

Conforme uma revisão de literatura relacionando-se os anos 2000 a 2017, ocorreram 188 casos de raiva humana no Brasil, com a maior parte das notificações registradas nas regiões Nordeste e Norte, salientando o surto ocorrido no final de 2017, em Barcelos, interior do Amazonas (VARGAS; ROMANO; MERCHÁN-HAMANN, 2019).

Diante do exposto, o objetivo do trabalho foi realizar ações de educação em saúde para a prevenção da raiva em humanos, utilizando material informativo e um questionário para entender a percepção da população sobre a doença no estado do Amazonas.

\section{METODOLOGIA}

A fim de obter embasamento teórico sobre a doença, foi realizada uma revisão bibliográfica a respeito da raiva em seres humanos no período de março a abril do ano de 2020, utilizando livros, revistas e artigos científicos. Além disso, houve a criação de uma página na rede social Instagram, denominada “@contraraiva_”, onde foram divulgados conteúdos autorais de cunho informativo e didático com informações acerca desta enfermidade. Na página e em outras redes sociais, foi divulgado um questionário anônimo, criado a partir da plataforma Google Forms, contendo 15 questões, que foi disponibilizado para ser respondido pelo público geral dos dias 12 a 23 de maio de 2020, no qual os dados obtidos foram tabulados em planilhas do Microsoft Excel, para posterior análise em gráficos e tabelas para a melhor compreensão dos resultados. Os mesmos demonstraram de forma qualitativa e quantitativa o nível de conhecimento básico da população residente no Amazonas, no que se refere às características da raiva em humanos.

\section{RESULTADOS E DISCUSSÃO}

O público contemplado pelo questionário foi de 694 participantes. Este grupo foi composto em maior parte por 50,9\% (353/694) de pessoas com idade entre 18 e 24 anos e 22,3\% (155/694) na faixa etária entre 24 e 40 anos.

Inicialmente 79,8\% (554/694) afirmaram já ter ouvido falar sobre a raiva e 20,2\% (140/694) afirmaram que não. De Lima Lovadini et al. (2019) em seu estudo observaram que 97,25\% (389/400) dos participantes afirmaram ter ouvido falar sobre a doença. Diante destes dados, pode-se perceber que a raiva é uma doença com a qual a maioria da população já teve informação em algum momento da vida. 
Quanto aos animais que podem transmitir a raiva, 31,6\% (219/694) responderam que somente o cão, 18,3\% (127/694) marcou a opção de que todos, menos ovelha e o rato podem transmitir, 10,7\% (74/694) acreditavam que animais silvestres em geral, 1,4\% (10/694) o rato, 1,0\% (7/694) o gato, para cavalo e ovelha $0,1 \%$ (1/694) para cada uma destas opções e 36,7\% (255/694) dos participantes respondeu todos. Percebe-se que de modo geral os participantes possuem o conhecimento que a transmissão pode ser feita por espécies de mamíferos, no entanto as ordens relativas a reservatórios importantes no contexto da saúde pública são: Chiroptera e Carnivora (KOTAIT et al., 2007).

Os participantes tiveram que responder qual o tipo de agente etiológico da doença e 57,8\% (401/694) escolheram a opção vírus, 23,9\% (166/694) a opção bactéria, 11,0\% (76/694) protozoário e 7,3\% (51/694) acreditava não se tratar de nenhum dos citados.

Sobre os três ciclos de transmissão da doença 84,6\% (587/694) afirmaram desconhecer. No entanto, 66,7\% (463/694) afirma saber como a doença é contraída e 53,7\% (373/694) afirma saber como se prevenir da doença. Apesar dos participantes do presente estudo afirmarem ter contato com alguma informação sobre a doença ainda há a necessidade de divulgação de maiores informações, pois quanto mais ela for conhecida, maior será a preocupação com estratégias de prevenção, visto que há relatos de melhoria dos conhecimentos por parte da população após ações de educação em saúde (MOREIRA et al., 2016; COSTA et al., 2017).

A vacinação de cães e gatos constitui uma medida profilática, 38,5\% (267/694) dos entrevistados afirmaram levar o animal ao médico veterinário para realização da vacina antirrábica anualmente, 22,2\% (154/694) afirmaram realizar a vacinação anual por meio de campanhas da prefeitura, 13,4\% (93/694) realizavam a vacinação de forma não anual, 4,2\% (29/694) afirmaram nunca ter vacinado o animal de estimação e 21,8\% (151/694) não possuíam animais de estimação. Além desta medida, cabe ressaltar também que o esquema de profilaxia da raiva humana e evitar contato com morcegos ou outros animais silvestres diretamente, estão entre ações de prevenção e controle desta doença (BRASIL, 2020).

Quando questionados sobre buscar atendimento médico em caso de mordida por algum animal 46,4\% (322/694) afirmaram não terem sido mordidos, 32,6\% (226/694) afirmaram não ter procurado assistência e somente $21,0 \%(146 / 694)$ procuraram atendimento médico.

Ao final do questionário os participantes responderam sobre o conhecimento de casos da doença no estado do Amazonas, 65,6\% (455/694) responderam não saber, 31,7\% (220/694) responderam sim e 2,7\% (19/619) responderam que não existem casos. Tal dado é preocupante, visto que a região Norte, juntamente com o Nordeste, é responsável por grande parte das notificações da doença, tendo o Amazonas uma ocorrência recente de surto em 2017, no município de Barcelos (VARGAS, ROMANO E MERCHÁN-HAMANN, 2019). 


\section{CONCLUSÃO}

O presente estudo ressalta a importância da realização de atividades de educação em saúde para a sensibilização da população a respeito da raiva humana. As análises das respostas ao questionário quanto à percepção do público em relação às postagens nas redes sociais possibilitaram a obtenção de noções da população em relação ao tema, permitindo a apuração dos tópicos mais relevantes a serem abordados em demais projetos e ações de extensão sobre a raiva humana. A partir dos resultados obtidos pelo questionário, percebe-se a carência de informação das pessoas principalmente em relação a ocorrência de casos no estado e também sobre os ciclos de transmissão, portanto tais pontos podem ser enfatizados em ações voltadas para a educação em saúde para prevenção da raiva humana no Amazonas.

\section{PRINCIPAIS REFERÊNCIAS}

AZEVEDO, J. P; OLIVEIRA, J. C. P.; PALMEIRA, P. A.; FORMIGA, N. V. L.; BARBOSA, V. S. A. Avaliação dos atendimentos da profilaxia antirrábica humana em um município da Paraíba. Cad. saúde colet. [Internet]. 2018 Mar [citado em 01 out. 2018]; 26( 1 ): 7-14. Disponível em: http://www. scielo.br/scielo.php?script=sci_arttext\&pid=S1414-462X2018000100007\&lng=en. http://dx.doi. org/10.1590/1414-462x201800010261.

DE LIMA LOVADINI, V. et al. Percepção e práticas da população atendida nos serviços primários de saúde sobre a Raiva. Revista Enfermagem Atual in Derme, v. 90, n. 28, 2019.

KIMURA, L. M. S.; JUNIOR, J. V. D. Raiva. In: Virologia humana e veterinária. SIMÕES, R. S. Q (ed). Thieme Revinter: Rio de Janeiro, p: 305-316, 2019.

VARGAS, A; CASTRO, A. L. M; CALDAS, E. P; KOTAIT, I; PEREIRA, L. R. M; TAKAOKA, N. Y; CUNHA, R. S; OLIVEIRA, R. C; NISHIOKA, S. A; ROCHA, S. M. Secretaria de Vigilância em Saúde. Guia de Vigilância em Saúde. $3^{\circ}$ ed. Ministério da Saúde. Brasília, DF. 2019.

WADA, M. Y.; ROCHA, S. M.; MAIA-ELKHOURY, A. N. S. Situação da raiva no Brasil, 2000 a 2009. Epidemiol Serv Saúde [Internet]. 2011 out-dez [citado 2019 fev 26];20(4):509-18. Disponível em: http://scielo.iec.gov.br/pdf/ess/v20n4/v20n4a10.pdf doi: 10.5123/S1679-49742011000400010. 